\title{
The Measurement of Thrombin in Clotting Blood by Radioimmunoassay
}

\author{
Marc A. Shuman and Philip W. Majerus \\ From the Division of Hematology-Oncology, Departments of Internal Medicine and Biochemistry, \\ Washington University School of Medicine, St. Louis, Missouri 63110
}

A B S T R A C T We have developed a radioimmunoassay for human thrombin using rabbit anti-human thrombin IgG. The assay can measure $2 \mathrm{ng}$ thrombin/ml plasma, 500 -fold more sensitive than clotting assays. Human prothrombin is less reactive in the assay than thrombin by at least four orders of magnitude, and there is no demonstrable cross-reactivity with human factor $\mathrm{X}_{\mathrm{a}}$, the clotting factor structurally most similar to thrombin. The assay does not detect thrombin bound to antithrombin III. Using the assay, we have demonstrated that plasma from 20 normal subjects does not contain detectable thrombin.

We measured thrombin generation in clotting blood in polypropylene tubes and observed that thrombin appears $(\cong 3 \mathrm{ng} / \mathrm{ml}$ ) within $45 \mathrm{~s}-5$ min after venipuncture. This material is thrombin, not intermediates of prothrombin activation, since it disappears after addition of heparin, which promotes thrombinantithrombin III complex formation. After a plateau of 2-10 min, there is further thrombin generation, which results in clotting after $15-27 \mathrm{~min}$ at a level of 40-50 $\mathrm{ng}$ thrombin/ml.

The thrombin generated 9-25 min before clotting may activate factors V and VIII and stimulate platelet aggregation and release. In contrast, the cascade hypothesis assigns a role for thrombin only late in blood clotting. Radioimmunoassay of thrombin and other clotting factors will be useful for clinical and physiological studies of blood clotting especially since the assay seems specific for thrombin and is independent of other activities that affect bioassays.

\section{INTRODUCTION}

Studies designed to clarify the processes involved in blood coagulation have been limited in the past by the available technology for measuring the individual

Received for publication 23 April 1976 and in revised form 19 July 1976. components. The classical approach has been to assay the involved enzymatic factors on the basis of their functional activity. In most cases this involved using plasma deficient in the enzyme or factor to be assayed, or plasma from which the particular factor has been removed. This approach has been limited by the availability of factor-deficient plasma and by the difficulty of preparing plasma selectively and totally deficient in individual factors. Furthermore, these assays are usually indirect in that the end-point is based on the clotting of fibrinogen, which in turn is dependent on several other factors.

The standardized fibrinogen clotting assay is accurate at concentrations of thrombin greater than 1 $\mu \mathrm{g} / \mathrm{ml}(3 \mathrm{U} / \mathrm{ml})$ (1). A number of clotting factors other than fibrinogen, including factors $\mathrm{V}$ and VIII and platelets, are affected by thrombin concentrations lower than $1 \mu \mathrm{g} / \mathrm{ml}$ when studied in vitro (2-4). It is possible that low levels of thrombin generated early in hemostasis are important to the overall process. The clotting assay has limited usefulness to study these processes in whole blood because at the level of thrombin detectability clotting takes place and serum is formed.

Considerable information has been gathered recently on the activation of prothrombin by factors $\mathrm{X}_{\mathrm{a}}$, and $\mathrm{V}, \mathrm{Ca}^{2+}$, and phospholipid by analysis of the activation reaction products by sodium dodecyl sulfate (SDS) ${ }^{1}$-polyacrylamide gel electrophoresis (5-12). This technique has permitted identification of the intermediates of prothrombin activation and the sites of cleavage during activation. This approach, however, has several limitations for study of the physiology of hemostasis. First, to reproduce physiologic conditions accurately, one must include all components participating in the reaction. Second,

\footnotetext{
${ }^{1}$ Abbreviations used in this paper: ACD, acid citrate dextrose; DIP-thrombin, diisopropylphosphoryl thrombin; $\mathrm{iP}_{\mathrm{r} 2} \mathrm{PF}$, diisopropyl fluorophosphate; SDS, sodium dodecyl sulfate.
} 
to start the reaction with an activated zymogen, i.e., factor $X_{a}$, is arbitrary and concedes the initial activating steps. Third, the actual quantitative relationships of the various activated factors in clotting blood are unknown, and thus reactions carried out in buffered systems are arbitrary in regard to the concentration of factors used.

The present study was designed to provide a technique whereby the kinetics of thrombin formation can be investigated under more physiologic conditions in the presence of other activities and with greater sensitivity. We describe a radioimmunoassay for measuring human thrombin in nanogram quantities. Thrombin levels in blood can be determined and appear to reflect active thrombin. Using the assay we have measured the generation of thrombin in clotting blood.

\section{METHODS}

Human thrombin used in these experiments was either purified as previously described $(4,13)$ or was obtained from Dr. J. W. Fenton, II, Division of Laboratories and Research, New York State Department of Health, Albany, $\mathrm{N}$. Y. Both preparations were very similar in specific activity (2700-2800 NIH U/mg) and $\alpha$-thrombin content (5), (98.6\% and $99.7 \%$, respectively) based on $\left[{ }^{[4} \mathrm{C}\right]$ diisopropyl fluorophosphate $\left(\mathrm{iP}_{\mathrm{r} 2} \mathrm{PF}\right)$ incorporation followed by SDSpolyacrylamide gel electrophoresis. Human prothrombin was purified by a modification of the procedure of Owen et al. (8) for bovine prothrombin. Cohn fraction III paste (courtesy of Dr. Milan Wickerhauser, National Fractionation Center, American Red Cross, Bethesda, Md.) was the starting material rather than plasma. The human prothrombin when fully activated had a specific activity of $1,400 \mathrm{NIH}$ thrombin U/mg prothrombin. Bovine thrombin was purified from topical thrombin (Parke, Davis \& Co., Detroit, Mich.) by the method of Glover and Shaw (14). It had a specific activity of $2,200 \mathrm{NIH} \mathrm{U} / \mathrm{mg}$. Bovine prothrombin was kindly provided by Dr. C. M. Jackson (8). It had a specific activity of $1,240 \mathrm{NIH}$ thrombin U/mg prothrombin when fully activated.

Human factor $\mathrm{X}$ was a gift from Dr. Robert Rosenberg (11). Activation was accomplished by incubating factor $\mathrm{X}$ in $0.15 \mathrm{M} \mathrm{NaCl}, 0.02 \mathrm{M}$ Tris- $\mathrm{HCl}, \mathrm{pH} 7.7,0.01 \mathrm{M} \mathrm{CaCl}_{2}$ containing $50 \mu \mathrm{l} / \mathrm{ml}$ of a stock suspension of rabbit brain cephalin (Sigma Chemical Co., St. Louis, Mo.), and 0.1 $\mathrm{mg} / \mathrm{ml}$ of the venom from Vipera Russellii (snake venom, Sigma) for $30 \mathrm{~min}$ at $20^{\circ} \mathrm{C}$. Factor $\mathrm{X}_{\mathrm{a}}$ activity was assayed as previously described (15), with plasma deficient in factors VII and X (Sigma).

Preparation of human antithrombin III. Antithrombin III was purified by a modification of the method described by Yin et al. (16). To $500 \mathrm{ml}$ of fresh human plasma adsorbed twice with $100 \mathrm{mg} / \mathrm{ml}$ barium sulfate, $200 \mathrm{ml}$ of buffer $(0.15 \mathrm{M} \mathrm{NaCl}, 0.02 \mathrm{M}$ Tris- $\mathrm{HCl}, \mathrm{pH} 7.4,0.02 \%$ sodium azide) was added. The $\mathrm{pH}$ was adjusted to 7.2 with $0.1 \mathrm{~N} \mathrm{HCl}, 50 \mathrm{ml}$ of $4 \%$ 6,9-diamino-2-ethoxyacridine lactate (Rivanol, Sigma) in ethanol was added, and the mixture was stirred for $13 \mathrm{~h}$ at $4^{\circ} \mathrm{C}$. The precipitate was removed by centrifugation at $10,400 \mathrm{~g}$ for $20 \mathrm{~min}$. The supernatant was dialyzed against buffer $(0.15 \mathrm{M} \mathrm{NaCl}, 0.02 \mathrm{M}$ Tris- $\mathrm{HCl}, \mathrm{pH} 7.4,0.02 \%$ sodium azide) with several changes for 5 days and was then applied to a $5 \times 13.7-\mathrm{cm}$ column of heparin-agarose $(17)^{2}$ equilibrated with the same buffer. The column was washed with the same buffer until the $A_{280}$ of the eluate was 0.04 , then eluted with $0.5 \mathrm{M} \mathrm{NaCl}$ $0.02 \mathrm{M}$ Tris- $\mathrm{HCl}, \mathrm{pH} 7.4$, and $0.02 \%$ sodium azide until the $A_{280}$ of the effluent was zero. Next, the column was eluted with $2.0 \mathrm{M} \mathrm{NaCl}$ in the above buffer. A single $A_{280}$ peak was obtained, and the fractions were pooled. After dialysis against buffer $(0.15 \mathrm{M} \mathrm{NaCl}, 0.02 \mathrm{M}$ Tris$\mathrm{HCl}, \mathrm{pH}$ 7.4), the material was assayed for antithrombin III activity. The antithrombin III was homogeneous based on SDS-polyacrylamide gel electrophoresis. Protein concentration was measured by absorption at $280 \mathrm{~nm}$ with an $A_{280} 1 \%$ of 5.7 (18).

Assay of antithrombin III activity. An appropriate dilution of the sample to be assayed was incubated at $37^{\circ} \mathrm{C}$ in $0.5 \mathrm{ml}$ of $0.14 \mathrm{M} \mathrm{NaCl}$ and $0.01 \mathrm{M}$ Tris- $\mathrm{HCl}, \mathrm{pH} 7.4$ containing $2 \mathrm{U}$ of heparin and $2.5 \mathrm{U}$ of thrombin. After $10 \mathrm{~min}, 0.1 \mathrm{ml}$ was removed and added to $0.3 \mathrm{ml}$ of the standard thrombin assay mixture and $0.1 \mathrm{ml}$ of fibrinogen $4 \mathrm{mg} / \mathrm{ml}$. From the clotting time and comparison to a parallel incubation without antithrombin III, the amount of thrombin inhibited was determined. Approximately $2.2 \mu \mathrm{g}$ of antithrombin III inhibited $1 \mu \mathrm{g}$ of thrombin.

Radioiodination of thrombin and antithrombin III. Carrier-free [ $\left.{ }^{125} \mathrm{I}\right]$ and $\left[{ }^{131} \mathrm{I}\right]$ sodium iodide, $70-95 \mathrm{mCi} / \mathrm{ml}$ and $450 \mathrm{mCi} / \mathrm{ml}$, respectively, were obtained from Mallinckrodt Inc., St. Louis, Mo.; chloramine-T was purchased from Eastman Kodak Co., Rochester, N. Y.; sodium metabisulfite was from Fisher Scientific Co., Pittsburgh, Pa.; Sephadex G25-80 was from Pharmacia Fine Chemicals, Inc., Piscataway, N. J.; and bovine serum albumin (crystallized and lyophilized) was from Sigma Chemical Co.

Thrombin. Iodination was performed by a modification of the technique described by Hunter (19). Chloramine-T ( $5 \mu \mathrm{l}$ of a $4.0 \mathrm{mg} / \mathrm{ml}$ solution) was added to human thrombin, $3 \mu \mathrm{g}$ in $0.05 \mathrm{ml}$ of $0.75 \mathrm{M} \mathrm{NaCl}-0.05 \mathrm{M}$ sodium phosphate, $\mathrm{pH} 6.5$, containing $1.25 \mathrm{mCi}$ of [125I] sodium iodide. After $10-15 \mathrm{~s}, 0.01 \mathrm{ml}$ of sodium metabisulfite, $2.4 \mathrm{mg} / \mathrm{ml}$, was added. The reaction mixture was brought to $0.50 \mathrm{ml}$ with the above buffer containing $0.5 \%$ albumin, applied to a 12 $\times 0.9-\mathrm{cm}$ Sephadex G25-80 column, and eluted with the same buffer. Thrombin radioiodinated in this manner showed no significant loss of clotting activity.

Antithrombin III. The technique was similar to that used with thrombin except that iodination was for $30 \mathrm{~s}$ and the buffer was $0.15 \mathrm{M} \mathrm{NaCl}, 0.01 \mathrm{M}$ Tris- $\mathrm{HCl}, \mathrm{pH} 7.5$.

The [125I] thrombin was adjusted to contain $0.01 \mathrm{M} \mathrm{iP}_{\mathrm{r} 2} \mathrm{PF}$ with $1.0 \mathrm{M} \mathrm{iP} \mathrm{P}_{\mathrm{r} 2} \mathrm{PF}$ in isopropanol (Sigma Chemical Co.), and the unreacted ${ }_{i} \mathrm{P}_{\mathrm{r} 2} \mathrm{PF}$ was removed by Sephadex G2580 chromatography. ${ }^{125}$ I-diisopropylphosphoryl thrombin (DIP-thrombin) so prepared was stored at $-20^{\circ} \mathrm{C}$. Decline in the net precipitable radioactivity and increase in the nonspecific precipitable radioactivity in the radioimmunoassay were used as indications of the deterioration of the tracer and occurred variably after $3 \mathrm{wk}$ of storage.

Preparation of antibody. The rationale and method of immunization of rabbits with human DIP-thrombin have been described (4). After primary immunization with $1.0 \mathrm{mg}$ of human thrombin, booster immunizations were carried out at 4-6-wk intervals with $0.2 \mathrm{mg}$ of thrombin. The titer of the antisera was assessed by measuring the degree of inhibition of the conversion of fibrinogen to fibrin by thrombin. The antithrombin antibody used in these experiments described below (HAT-35) was obtained approximately 5 mo after initial immunization; $250 \mathrm{U}$ of thrombin were neutralized by $1 \mathrm{ml}$ of HAT-35 antiserum (4).

\footnotetext{
${ }^{2}$ Prepared by Dr. C. M. Jackson.
} 
The IgG fraction of antisera was prepared by DEAE cellulose (DE23, Whatman Chemicals, Div. W. \& R. Balston, Kent, England) chromatography (20).

Radioimmunoassay. The reactions were carried out at $0^{\circ} \mathrm{C}$ in a total volume of $0.2 \mathrm{ml}$ in $1.5 \mathrm{ml}$ Eppendorf micro test tubes (Brinkmann Instruments, Inc., Westbury, N. Y.), previously soaked in $0.5 \%$ albumin.

The incubation buffer and the buffer in which all dilutions were made was $0.15 \mathrm{M} \mathrm{NaCl}, 0.01 \mathrm{M}$ Tris- $\mathrm{HCl}, \mathrm{pH} 7.4$, and contained $0.5 \%$ albumin and $0.01 \mathrm{M}$ benzamidine (Aldrich Chemical Co., Inc., Milwaukee, Wis., the latter to inhibit proteolysis). The reaction mixture contained the following: test sample, $5 \mu \mathrm{l}(0.05-0.1 \mu \mathrm{g}$ of protein) of anti-human thrombin IgG (an amount that gives 40$60 \%$ precipitation of ${ }^{125}$ I-DIP-thrombin tracer; with excess antibody, $82 \%$ of tracer is precipitable) and $2 \mu \mathrm{l}(5 \mu \mathrm{g}$ of protein) of non-immune rabbit IgG. After incubation for $2 \mathrm{~h}$, $5 \mu$ l of ${ }^{125}$ I-DIP thrombin $\left(10^{4} \mathrm{cpm} / 0.1 \mathrm{ng}\right)$ was added, and the incubation was continued for an additional $16 \mathrm{~h}$. Preincubation of test samples with antithrombin IgG for $2 \mathrm{~h}$ before addition of the labeled antigen resulted in a twofold increase in sensitivity of the assay; longer preincubation did not further increase the sensitivity. The IgG fraction of goat anti-rabbit IgG antisera (antisera obtained from Gateway Immunosera Co., Cahokia, Ill.), $0.2 \mathrm{mg}$ in $15 \mu \mathrm{l}$, was then added to each reaction mixture. Incubation was continued for an additional $6 \mathrm{~h}$. After addition of $0.8 \mathrm{ml}$ of buffer, the immunoprecipitates were collected by centrifugation at $14,000 \mathrm{~g}$ for $15 \mathrm{~min}$. The supernatant solutions were removed, and the test tubes containing the precipitated ${ }^{125}$ I-DIP-thrombin were counted in a Packard gamma scintillation spectrometer (Packard Instrument Co., Inc., Downers Grove, Ill.). Each reaction was performed in duplicate. The amount of tracer specifically bound to antithrombin IgG was determined after subtracting the amount of radioactivity precipitated in incubations where only nonimmune IgG was present. The radioactivity precipitated in these samples resulted in correction of less than $2.5 \%$ of the total amount of tracer precipitable by immune IgG.

In experiments where plasma was assayed, the volume of the reaction mixture was also $0.2 \mathrm{ml}$, of which $0.1 \mathrm{ml}$ was plasma. Thus, 1-100 $\mu \mathrm{l}$ of test plasma was added to sufficient control plasma (see below) to provide a total of 0.100 $\mathrm{ml}$. In the standard displacement curve with unlabeled thrombin, control plasma was used. The assay was otherwise identical to that described above. For all assays, IgG fractions of antisera were used to avoid the problems created by the antisera-contained activated clotting factors.

Preparation of control plasma. Freshly drawn blood was anticoagulated with either acid citrate dextrose (ACD) ${ }^{3}$ or sodium heparin (Riker Laboratories, Northridge, Calif.) in a final concentration of $5 \mathrm{U} / \mathrm{ml}$. $\mathrm{iP}_{\mathrm{r} 2} \mathrm{PF}$ was added to a final concentration of $0.01 \mathrm{M}$ with $1 \mathrm{M} i \mathrm{P}_{\mathrm{r} 2} \mathrm{PF}$ in isopropanol, and the blood was kept at $\mathrm{O}^{\circ} \mathrm{C}$ for $15 \mathrm{~min}$. Then $0.5 \mathrm{M}$ benzamidine was added to a final concentration of $0.01 \mathrm{M}$, and the blood was centrifuged at $12,000 \mathrm{~g}$ for $15 \mathrm{~min}$. The plasma was then passed over an Amberlite CG-50 polymethylacrylic acid resin column (200-400 mesh particle size, Mallinckrodt Inc.) equilibrated in $0.15 \mathrm{M}$ $\mathrm{NaCl}$ (bed volume equal to twice the plasma volume). This column removed traces of thrombin efficiently since when ${ }^{125}$ I-DIP-thrombin in concentrations of $0.2-200$ $\mathrm{ng} / \mathrm{ml}$ was added to the plasma, more than $90 \%$ of the thrombin bound to the resin, based on the radioactivity remaining in the effluent plasma. Whether the latter actually reflected thrombin or was free iodide or other material was not investigated further.

${ }^{3} \mathrm{ACD}$ was used in 1:7 ( $\left.\mathrm{vol} / \mathrm{vol}\right)$ ratio in all experiments.
Radioimmunoassay of thrombin in normal subjects. Blood was drawn from 10 male and 10 female healthy subjects between the ages of 20 and 50 with 19-gauge needles. The first $5 \mathrm{ml}$ of blood collected was discarded. ACD was added as the anticoagulant to $10 \mathrm{ml}$ of blood, and samples were adjusted to contain $0.01 \mathrm{M}$ benzamidine with $0.5 \mathrm{M}$ benzamidine. Plasma obtained after centrifugation at $12,000 \mathrm{~g}$ for $15 \mathrm{~min}$ was assayed as described above.

Radioimmunoassay of thrombin in clotting blood. Blood was drawn through a 15-gauge needle (AE-6 plasma transfer set; Fenwal Inc., Walter Kidde \& Co., Inc., Ashland, Mass.). "Zero" time was considered to be when blood was initially seen entering the tubing attached to the needle. The first $10 \mathrm{ml}$ was discarded, and $30 \mathrm{ml}$ of blood was collected into a polypropylene tube and placed either on ice or at $22^{\circ} \mathrm{C}$. Portions of $1 \mathrm{ml}$ were taken from the pool at $1-\mathrm{min}$ intervals and added to tubes containing ACD or heparin $(60 \mathrm{U} / \mathrm{ml})$, and $1.0 \mathrm{M} \mathrm{iP}_{\mathrm{r} 2} \mathrm{PF}$ in isopropanol was added immediately (final concentration $0.01 \mathrm{M}$ ). Samples were kept on ice for $20 \mathrm{~min}$, and $0.5 \mathrm{M}$ benzamidine was then added to a final concentration of $0.01 \mathrm{M}$. Blood samples were centrifuged at $1,800 \mathrm{~g}$ for $10 \mathrm{~min}$, and the plasma was removed and immediately assayed for thrombin content.

Measurement of thrombin generation by radioimmunoassay after in vitro activation of prothrombin by factor $\mathrm{X}_{a}, \mathrm{Ca}^{2+}$, and phospholipid. Human prothrombin, 20 $\mu \mathrm{g} / \mathrm{ml}$, was incubated at $37^{\circ} \mathrm{C}$ in buffer $(0.15 \mathrm{M} \mathrm{NaCl}$, $0.02 \mathrm{M}$ Tris- $\mathrm{HCl}, \mathrm{pH} 7.4,2 \mathrm{mM} \mathrm{CaCl} \mathrm{Cl}_{2}$ ) containing $25 \mu \mathrm{l} / \mathrm{ml}$ of a stock suspension of rabbit brain cephalin. Bovine factor $\mathrm{X}_{\mathrm{a}}{ }^{2}, 0.5 \mathrm{U} / \mathrm{ml}$ was added, aliquots were removed at intervals, and further activation was inhibited by the addition of $0.05 \mathrm{M}$ EDTA and $1.0 \mathrm{iP}_{\mathrm{r} 2} \mathrm{PF}$ at final concentrations of $2 \mathrm{mM}$ and $0.01 \mathrm{M}$, respectively. Samples were kept at $0^{\circ}$ for $15 \mathrm{~min}$, and then $0.5 \mathrm{M}$ benzamidine was added to a final concentration of $0.01 \mathrm{M}$.

Immunoassay of thrombin-antithrombin III complex. Thrombin or DIP-thrombin, $1 \mu \mathrm{g}$ in $25 \mu \mathrm{l}$, and $20.0 \mu \mathrm{g}$ of ${ }^{131} \mathrm{I}$-antithrombin III in $0.07 \mathrm{ml}\left(5 \times 10^{5} \mathrm{cpm} / \mu \mathrm{g}\right)$ were added to heparin $(20 \mathrm{U})$ in $0.905 \mathrm{ml}$ of $0.15 \mathrm{M} \mathrm{NaCl}$, $0.01 \mathrm{M}$ Tris- $\mathrm{HCl}, \mathrm{pH} 7.4,0.5 \%$ albumin. A third reaction mixture was similar except that it contained neither native or DIP-thrombin. After $10 \mathrm{~min}$ at $37^{\circ} \mathrm{C}$, aliquots were removed from each reaction mixture, and thrombin concentration was determined by radioimmunoassay.

Determination of the thrombin content of the human factor $X_{a}$ preparation by clotting assay. Factor $\mathrm{X}$ was activated with Russell's viper venom as described above. A standard curve was constructed based on results of the fibrinogen clotting assay with small amounts of thrombin (0.01-5 $\mathrm{U} / \mathrm{ml}$ ) and used as a reference to estimate the thrombin content of the mixture containing factor $\mathrm{X}_{\mathrm{a}}$.

Effect of antithrombin IgG on the fibrinogen clotting activity of the $X_{a}$ preparation. $5 \mu \mathrm{g}$ of $\mathrm{X}_{\mathrm{a}}$ were incubated

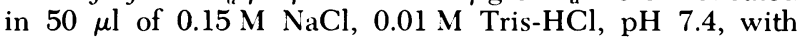
or without $4 \mu \mathrm{g}$ of antithrombin IgG for $7 \mathrm{~min}$ at $37^{\circ} \mathrm{C}$. The amount of thrombin present in each instance was determined based on the clotting time in comparison to a standard curve with thrombin.

The thrombin clotting assay was performed as described (20), with human fibrinogen prepared from fresh frozen plasma in one-half the standard volume to increase sensitivity $(21)$.

\section{RESULTS}

Thrombin radioimmunoassay. The radioimmunoassay of pure human thrombin was performed as described in Methods, and a standard curve is shown 


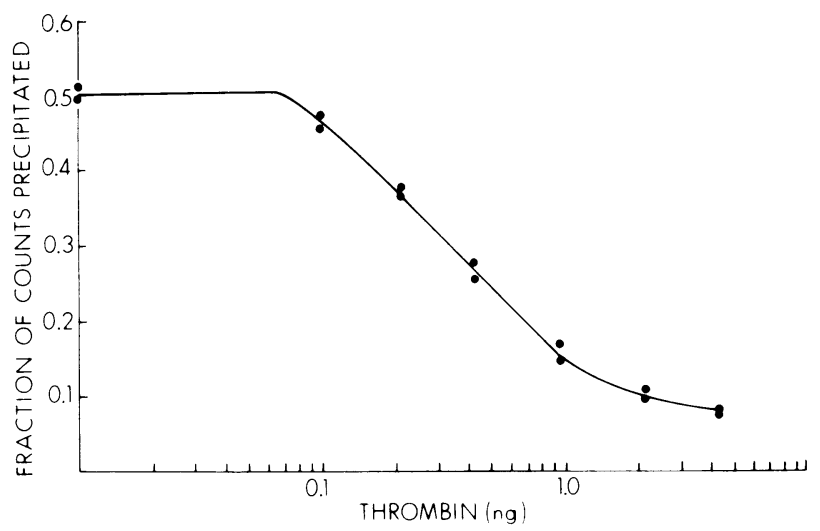

FIGURE 1 Standard curve of the radioimmunoassay of thrombin in buffer.

in Fig. 1. With the HAT-35 antibody, the assay is able to detect as little as $0.2 \mathrm{ng}$ or $5 \mathrm{fmol}$ of thrombin. There is complete displacement of ${ }^{125}$ I-DIP thrombin by $2 \mathrm{ng}$ of unlabeled thrombin. Results of duplicates can be used to indicate the precision of the assay. The specificity of the HAT-35 antibody for human thrombin is indicated in Fig. 2. There is only partial displacement (approximately 20\%) with bovine thrombin, indicating limited cross-reactivity. The result is consistent with our earlier observations of the limited cross-reactivity between human and bovine thrombin with antibodies to thrombin of both species (4). The human prothrombin preparation used in the experiment depicted in Fig. 2 was three orders of magnitude less effective than human thrombin at displacing tracer thrombin. Prothrombin is actually much less reactive, since this particular prothrombin preparation was contaminated with traces of thrombin not detectable by conventional means, i.e., SDS-polyacrylamide gel electrophoresis or clotting assay. This is

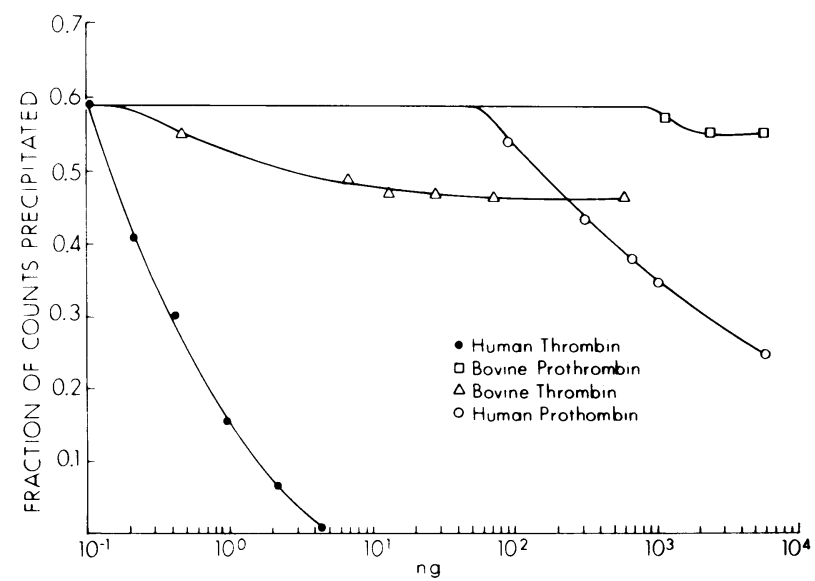

FiguRE 2 Specificity of anti-thrombin IgG for human thrombin. indicated by the fact that other prothrombin preparations were less reactive, giving $50 \%$ displacement of ${ }^{125} \mathrm{I}$-DIP thrombin at $10-100 \mu \mathrm{g} / \mathrm{ml}$. Furthermore, as shown below (Fig. 5), thrombin may be assayed in plasma in any assay system containing 50\% normal plasma, wherein the prothrombin concentration approximates $50 \mu \mathrm{g} / \mathrm{ml}$ without significant displacement of labeled thrombin. It is likely, however, that prothrombin does cross-react in the radioimmunoassay to a limited extent, since if the observed displacement with various prothrombin preparations were all due to traces of thrombin, the slope of the displacement curve should be the same as that observed with standard thrombin. In the experiment shown in Fig. 2 , the slope of the thrombin curve is 0.43 , while that of prothrombin is clearly different $(0.18)$. In other experiments, a consistent three- to 5 -fold difference in slope was seen between thrombin and prothrombin. That the displacement of ${ }^{125}$ I-DIP thrombin by prothrombin indicates true cross-reactivity rather than a nonspecific effect of the high concentration of protein is indicated by the fact that bovine prothrombin at high levels does not result in significant displacement of ${ }^{125}$ I-DIP-thrombin (Fig. 2). Also, it is possible that traces of prothrombin activation intermediates contaminating prothrombin, namely prethrombin 1 and prethrombin $2(22)$, are slightly reactive in the immunoassay. When cross-reactivity of the HAT-35 IgG with human prothrombin was tested by immunodiffusion, a less sensitive method than radioimmunoassay, no cross-reactivity was seen.

Cross-reactivity of human factor $X_{\mathrm{a}}$ with antithrombin IgG. Because the coagulation protein factors II, IX, and X are structurally similar and have probably evolved from a common ancestral gene (23), we determined the extent of cross-reactivity of factor $\mathrm{X}_{\mathrm{a}}$ with the HAT-35 antibody. As can be seen in Fig. 3, there is an apparent 2,000-fold difference in reactivity between thrombin and factor $\mathrm{X}_{\mathrm{a}}$. However, the slopes of the displacement curves are virtually identical-0.3. This suggests that the displacement seen with factor $X_{a}$ results from contamination of the factor $\mathrm{X}$ with traces of prothrombin, converted to thrombin by factor $\mathrm{X}_{\mathrm{a}}$ after activation. The contamination of factor $\mathrm{X}$ with $0.05 \%$ prothrombin could not be detected by SDS-polyacrylamide gel electrophoresis (the factor $\mathrm{X}$ gave a single band on electrophoresis). To confirm that the displacement seen by the factor $\mathrm{X}_{\mathrm{a}}$ preparation was due to thrombin and not true cross-reactivity, a clotting assay for thrombin was carried out with fibrinogen. The amount of thrombin in the preparation measured by this technique corresponds to $0.16 \%$ of the factor X protein (i.e. $5 \mu \mathrm{g}$ factor $X$ after activation clots fibrinogen in $109 \mathrm{~s}$ in the thrombin assay, which corresponds to $7 \mathrm{ng}$ thrombin as determined from a standard curve with 
thrombin.) Furthermore, when $4 \mu \mathrm{g}$ of antithrombin IgG, an amount that could inhibit the thrombin estimated to be present ( $7 \mathrm{ng}$ ), was incubated with $5 \mu \mathrm{g}$ of factor $\mathrm{X}$, the fibrinogen clotting time was markedly prolonged $(490 \mathrm{~s})$. These experiments demonstrate that the factor $X_{a}$ contains traces of thrombin that account for the displacement seen in the immunoassay.

Radioimmunoassay in plasma. We next adapted the thrombin radioimmunoassay to measure thrombin in human plasma. Special precautions were taken to prevent the potential artifactual formation of thrombin in vitro during the radioimmunoassay (see Methods). In preliminary experiments where varying amounts of ACD-anticoagulated plasma were added in place of buffer in the standard assay (0.001$0.1 \mathrm{ml}$ ), there was some displacement of ${ }^{125}$ I-DIP thrombin at $0.1 \mathrm{ml}$ of plasma; with several samples of plasma there was $5-30 \%$ displacement, corresponding to 1-3 ng thrombin/ml of plasma. The shallow slope of the curve, however, suggested that the material was not thrombin and that displacement was more likely due to the cross-reactivity of prothrombin or to some effect of an unidentified plasma component. In an attempt to prepare truly thrombinfree control plasma, we passed freshly drawn plasma over an Amberlite CG-50 column (Rohm \& Haas Co., Philadelphia, Pa.). As described in Methods, this procedure removes over $90 \%$ of the thrombin present in plasma. There was no significant difference in the immunoassay of plasma so treated, as compared to plasma not passed over the Amberlite column. This would indicate that the displacement of ${ }^{125}$ I-DIP thrombin by normal plasma is not due to the presence of traces of thrombin in anticoagulated plasma.

To avoid the problem of slight displacement of ${ }^{125}$ I-DIP thrombin in assays with varying plasma content, all assays were performed in the presence of a constant amount of plasma $(0.1 \mathrm{ml})$ in the total 0.2 $\mathrm{ml}$ reaction. Any cross-reactivity with prothrombin is "absorbed out" in each reaction mixture. As shown in Fig. 4, the assay was as sensitive when carried out in a reaction mixture containing $0.1 \mathrm{ml}$ plasma as in buffer (compare to Fig. 1). The amount of HAT$35 \mathrm{IgG}$ used in the plasma assay was 1.5- to 3-fold greater than that needed in the buffer assay to achieve an equivalent $50 \%$ precipitation of ${ }^{125}$ I-DIP thrombin. This is probably explained by either cross-reacting prothrombin and/or an effect of some other unidentified plasma component.

When either 0.010 or $0.1 \mathrm{ml}$ of plasma from each of 20 healthy volunteers was assayed, there was no detectable displacement of tracer ${ }^{125}$ I-DIP thrombin compared with the control, "thrombin-free" plasma (Fig. 4). This indicates that thrombin is not normally

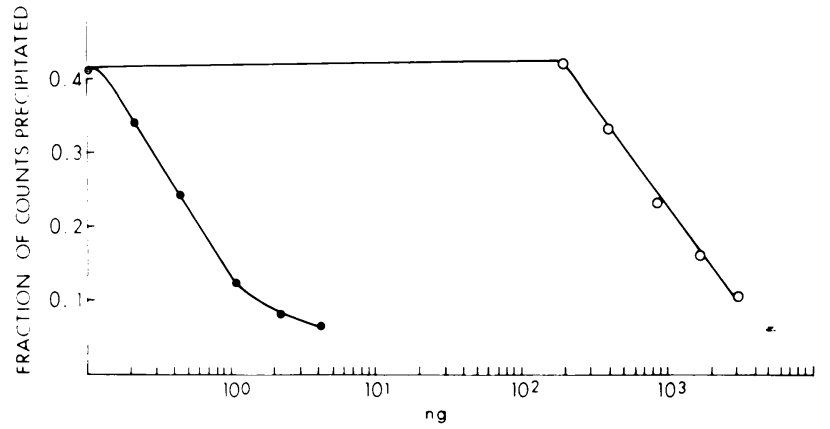

FIGURE 3 Radioimmunoassay of human factor $X_{a}$ preparation. Human factor $\mathrm{X}$ was activated with the venom from Vipera russellii as described in Methods and assayed for immunologic cross-reactivity with antithrombin IgG. , thrombin; $\mathrm{O}, \mathrm{X}_{\mathrm{a}}$.

present in human blood (within the limits of detectability of our system-less than $2.0 \mathrm{ng}$ of throm$\mathrm{bin} / \mathrm{ml}$ plasma), and suggests that no thrombin is generated during the radioimmunoassay procedure itself.

We have also measured plasma thrombin levels in a small series of 14 consecutive hospitalized patients who have had normal prothrombin times, and partial thromboplastin times as determined in the Barnes Hospital Hemostasis Laboratory (St. Louis, Mo.). These patients had slightly elevated plasma thrombin levels compared to laboratory personnel, $2.4 \pm 0.3 \mathrm{ng}(\mathrm{SD})$ thrombin $/ \mathrm{ml}$ plasma. Most of the patients had coagulation tests ordered as a routine preoperative workup. The highest thrombin level in this series was $3.2 \mathrm{ng}$ thrombin/ml plasma in a patient 1 day after common bile duct exploration and

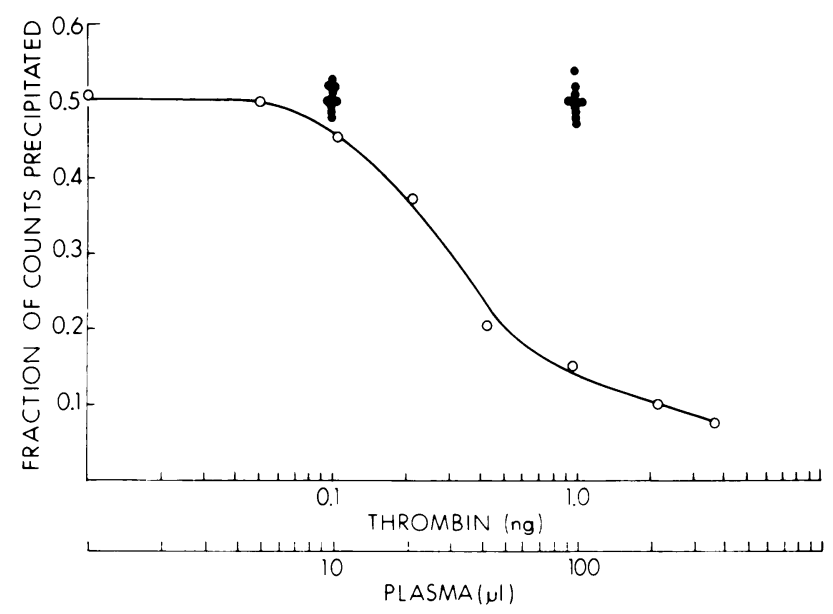

FIgURE 4 Standard curve of the radioimmunoassay of thrombin in plasma and assay of normal subjects. Plasma from 10 normal males was assayed at two levels: 10 and 100 $\mu$ l. O, test plasma; $\bigcirc$, DIP-thrombin. 

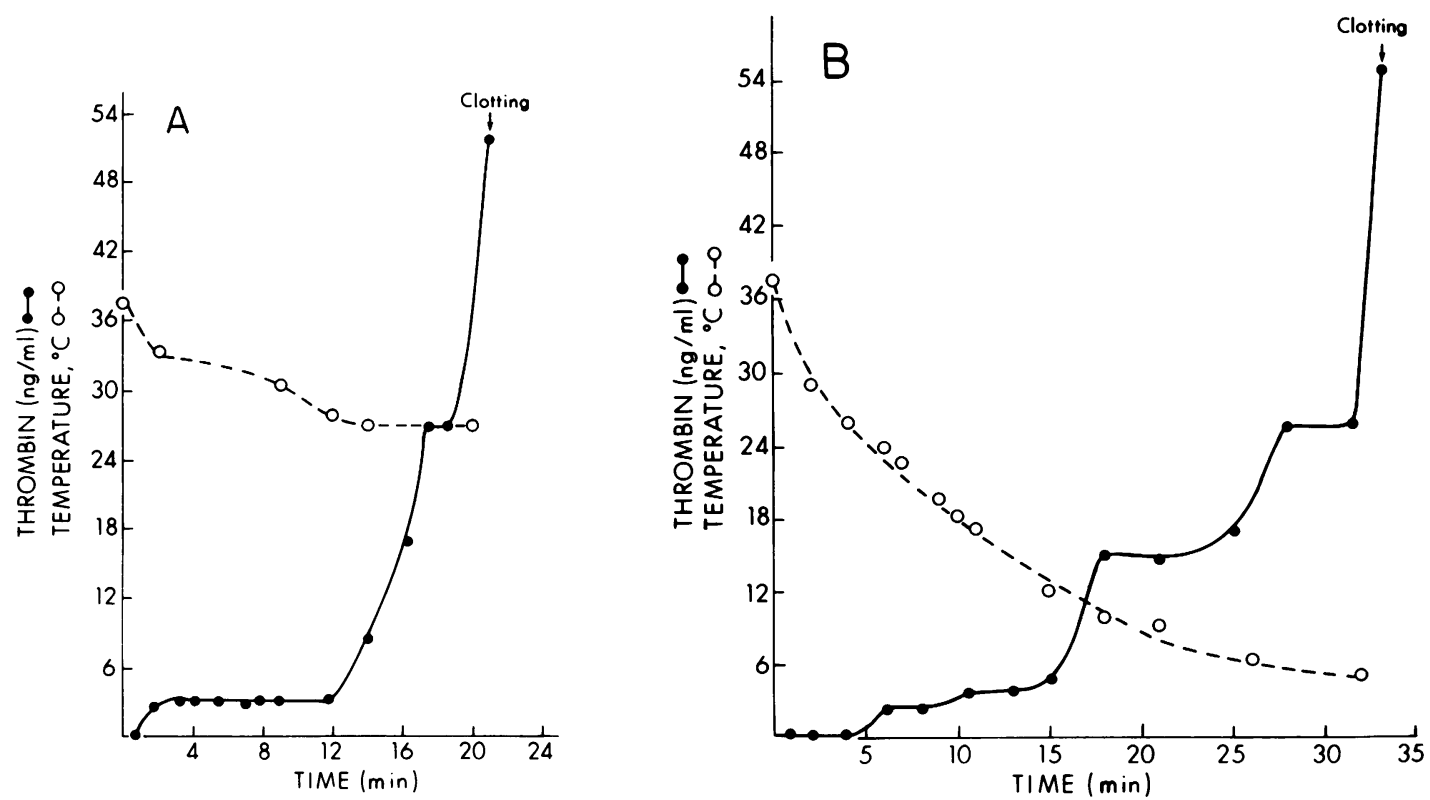

Figure 5 Radioimmunoassay of thrombin generated in blood during clotting. After venipuncture, $25 \mathrm{ml}$ of blood was collected into a polypropylene tube and kept at either room temperature $\left(22^{\circ} \mathrm{C}\right)$ or $0^{\circ} \mathrm{C}$. Aliquots were removed at 1 min intervals, anticoagulated with ACD; diisopropylphosphofluoridate (DFP), then benzamidine was added. The plasma was assayed for thrombin. $\mathrm{A}$, blood at $22^{\circ} \mathrm{C} ; \mathrm{B}$, blood at $0^{\circ} \mathrm{C} ; \boldsymbol{O}$, thrombin; $\mathrm{O}$, temperature of blood.

cholecystectomy. That plasma thrombin levels may be elevated is indicated from findings in two patients with marked disseminated intravascular coagulation associated with placenta previa. Both patients had elevated fibrin degradation products $(128 \mu \mathrm{g} / \mathrm{ml}$ and $64 \mu \mathrm{g} / \mathrm{ml})$ and hypofibrinogenemia $(<4.5 \mathrm{mg} /$ $100 \mathrm{ml}$ ). Plasma thrombin levels were $27 \mathrm{ng}$ thrombin/ $\mathrm{ml}$ and $32 \mathrm{ng}$ thrombin $/ \mathrm{ml}$ in these patients. $24 \mathrm{~h}$ later, after delivery, the thrombin level in one of the patients was reassayed at $4.5 \mathrm{ng}$ thrombin $/ \mathrm{ml}$. Whether measurement of plasma thrombin levels has any value in the evaluation of patients with thrombotic or hemorrhagic disorders awaits further study.

Efficiency of inhibition of factor $X_{\mathrm{a}}$ activation of prothrombin. It is conceivable that factor $\mathrm{X}_{\mathrm{a}}$ is not immediately inhibited by addition of anticoagulants and protease inhibitors, in which case thrombin could be generated in the samples during the radioimmunoassay. To examine this possibility, prothrombin was activated in vitro with factor $\mathrm{X}_{\mathrm{a}}, \mathrm{Ca}^{2+}$, and phospholipid, and the amount of thrombin generated over a 30 -min period was assayed. Factor $\mathrm{V}$ was omitted to allow relatively slow activation of prothrombin so that serial measurements would show a progressive increase in thrombin formation. Activation of prothrombin was inhibited as with plasma or blood samples (see below), by calcium chelation, inactivation of serine proteases first by addition of $\mathrm{iP}_{\mathrm{r} 2} \mathrm{PF}$ and then benzamidine, and incubation of samples at $0^{\circ} \mathrm{C}$. When inhibitors were added before factor $X_{a}$, no thrombin was formed. On the other hand, when samples were removed at intervals from the activation mixture, treated with inhibitors, and assayed, the thrombin concentration increased linearly from $1.9 \mathrm{ng}$ thrombin/ml at $3 \mathrm{~min}$ to $25 \mathrm{ng} / \mathrm{ml}$ at $30 \mathrm{~min}$. This indicates that factor $X_{a}$ activation of prothrombin is immediately inhibited when samples are treated as described above. Thus, the thrombin detected by radioimmunoassay represents thrombin generated before anticoagulant and inhibitors were added and is not the result of traces of thrombin formed during the radioimmunoassay.

Assay of thrombin formation in clotting whole blood. The cascade hypothesis is the current working model of many investigators of coagulation physiology and implies that thrombin is generated late in coagulation, just before the fibrin clot is formed. Alternatively, the concept that thrombin may be present very early in the coagulation process is an intriguing one. There is some experimental evidence to suggest a role for small amounts of thrombin before the clotting of blood (see Discussion). Because of the prior inability to measure thrombin in sub-microgram quantities, this hypothesis has not been adequately tested. We have measured the generation of thrombin in freshly 
drawn, clotting blood. The results of two experiments representative of eight such experiments are shown in Fig. 5A and B. The lag from the time of venipuncture until the first appearance of thrombin ranged up to $6 \mathrm{~min}$. Initially, a small quantity of thrombin, 2-3 ng (6-9 $\mathrm{mU} / \mathrm{ml}$ plasma) was seen. Subsequently, there was a variable lag in the further generation of additional thrombin, followed by a progressive but nonlinear generation of thrombin until at levels of $45-55 \mathrm{ng}$ thrombin $/ \mathrm{ml}(0.15 \mathrm{U} / \mathrm{ml})$ of plasma, clotting occurred. There was continued generation of thrombin after clotting with a maximum increase in thrombin levels about 30 min later $(300-$ $500 \mathrm{ng} / \mathrm{ml}$ plasma, data not shown). Finally approximately $1 \%$ of the prothrombin present in blood is converted to thrombin. In two of the eight experiments, thrombin appeared in the first sample after venipuncture, rather than after the lag described above.

Assay of antithrombin III-thrombin complex. Next, we determined whether the thrombin being measured in the immunoassay was bound to antithrombin III. Since it has been demonstrated that thrombin (but not DIP-thrombin) is bound to antithrombin III and formation of this complex is greatly facilitated by heparin (24), we performed experiments in which known amounts of native and DIPthrombin were added to plasma anticoagulated with

TABLE I

Radioimmunoassay of Thrombin in Plasma

\begin{tabular}{cc}
\hline Amount added & Amount detected \\
\hline$n g / m l$ & $n g / m l$ \\
Heparin & \\
Thrombin & $<2$ \\
20 & 8.7 \\
200 & 80 \\
2,000 & \\
DIP-Thrombin & 29 \\
20 & 183 \\
200 & 2,170 \\
2,000 & \\
ACD & \\
Thrombin & 17,21 \\
$20^{*}$ & 43 \\
$40 \ddagger$ & 35 \\
$50 \ddagger$ & \\
DIP-thrombin & 21 \\
20 & \\
\hline
\end{tabular}

Thrombin or DIP-thrombin was added to plasma containing $0.01 \mathrm{M}$ benzamidine and anticoagulated with either ACD or heparin $(20 \mathrm{U} / \mathrm{ml})$. Samples were incubated at $37^{\circ} \mathrm{C}$ for 10 min, then assayed.

* Two separate experiments.

† Sample clotted during 10-min incubation.

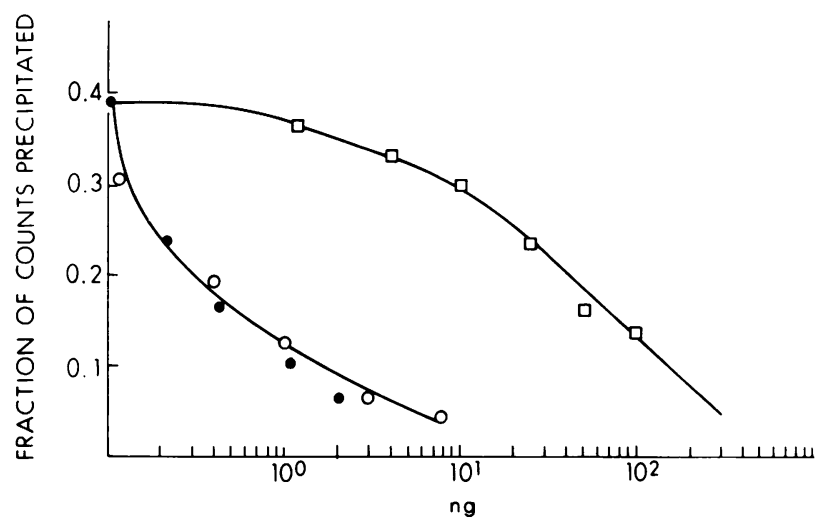

FIgURE 6 Radioimmunoassay of thrombin-antithrombin III complex. Native or DIP-thrombin, $1 \mu \mathrm{g} / \mathrm{ml}$, was incubated with heparin and antithrombin III for $10 \mathrm{~min}$ at $37^{\circ} \mathrm{C}$, as described in Methods. Aliquots were assayed for thrombin. , standard curve with thrombin; $O$, DIP-thrombin-antithrombin III incubation; $\square$, thrombin-antithrombin III incubation.

either ACD or heparin. As shown in Table I, less than $5 \%$ of thrombin added to heparinized plasma was detected by the radioimmunoassay, while there was good correlation between the amount of DIPthrombin added to heparinized plasma and the amount detected by radioimmunoassay. In similar experiments using ACD plasma, there was little difference in recovery of either DIP-thrombin or native thrombin as measured by radioimmunoassay. The latter experiments suggest that antithrombin III is relatively ineffective in binding thrombin in plasma in the absence of heparin.

These experiments did not distinguish, however, between a markedly decreased affinity of the antithrombin IgG for the antithrombin III-thrombin complex or complete absence of cross-reactivity between the antibody and the complex, with binding of the antibody to a small amount of thrombin not bound to antithrombin III. To resolve this question, ${ }^{131} \mathrm{I}-$ antithrombin III was incubated with equal amounts of either native or DIP-thrombin and the amount of thrombin present was determined by radioimmunoassay. As can be seen in Fig. 6, there is 100-fold less thrombin detected by radioimmunoassay in the thrombin-antithrombin III incubation mixture than in the DIP-thrombin-antithrombin III incubation. No ${ }^{131}$ I-antithrombin III was present in either immune precipitate, indicating that rather than 100 fold less cross-reactivity of the antithrombin IgG with the thrombin-antithrombin III complex, $1 \%$ of the native thrombin was not bound to antithrombin III, and that $1 \%$ displaced the tracer ${ }^{125}$ I-DIP-thrombin in the radioimmunoassay.

We used these observations to corroborate further that what we were measuring early in the clotting 


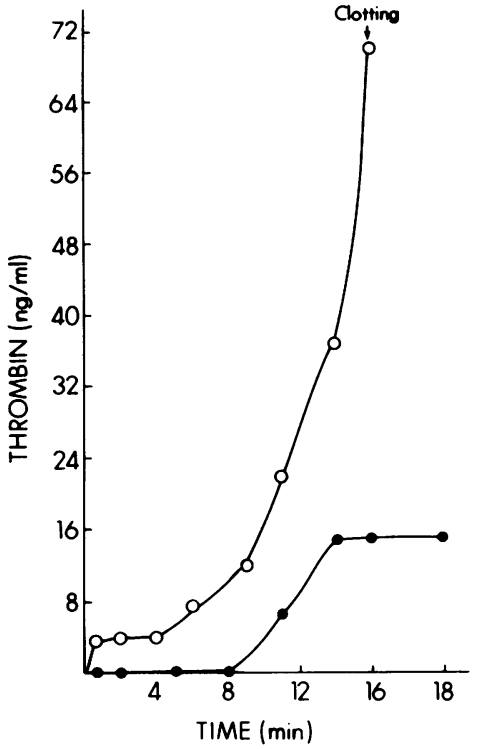

FIGURE 7 Radioimmunoassay of thrombin and thrombinantithrombin III in clotting blood. The experiment was carried out as described in Fig. 5A except that aliquots of blood were anticoagulated with either ACD or heparin. O, ACD, 1:7 (vol/vol); O, heparin, $60 \mathrm{U} / \mathrm{ml}$.

process was in fact thrombin. Duplicate aliquots of blood were taken at frequent intervals during clotting and anticoagulated with either ACD or heparin. Thrombin levels were measured and the results are shown in Fig. 7. In this experiment, thrombin was detected as $45 \mathrm{~s}$ in ACD plasma but not until 10 min in heparinized plasma. This strongly suggests that what is measured in ACD plasma is thrombin rather than the prothrombin intermediates, since the failure to detect displacement with heparinized plasma implies that the immunoreactive material is now bound to antithrombin III and therefore will not bind to the antithrombin antibody. The amount of thrombin we were able to measure in the late samples of heparinized blood was reduced by delaying for 30 min the addition of $\mathrm{iP}_{\mathrm{r} 2} \mathrm{PF}$ to the blood samples. It appears that when $\mathrm{iP}_{\mathrm{r} 2} \mathrm{PF}$ is added to the blood immediately after it is anticoagulated, much of the thrombin present is converted to DIP-thrombin before it can bind to antithrombin III, in spite of the presence of heparin.

\section{DISCUSSION}

Densen was able to make antibodies to clotting factors II, VII, IX, and X from bovine and human plasma (25); however, the antigens used for immunization were not homogeneous, and consequently antibodies to the respective factors showed significant cross-reactivity when assayed by clotting tests. Since then, specific antibodies have been made to a variety of purified preparations of both bovine and human clotting factors $(23,26-33)$. Hart et al. have reported a radioimmunoassay for plasmin (34).

The assay described here is highly sensitive and specific for human thrombin. As little as $2 \mathrm{ng} / \mathrm{ml}$ can be detected. Furthermore, plasma samples can be readily assayed without prior preparative procedures within approximately $24 \mathrm{~h}$.

The antithrombin antibody is specific for human thrombin as evidenced by the very limited crossreactivity with bovine thrombin. There was no crossreactivity with human factor $X_{a}$; there is approximately 10,000-fold less reactivity with human prothrombin than with human thrombin, and thus the zymogen does not significantly interfere with the thrombin assay in plasma. It appears that the prothrombin activation intermediates do not cross-react significantly when thrombin is assayed in plasma. This does not indicate that the antibody does not recognize determinants on these molecules, only that in the presence of a large concentration of prothrombin small amounts of the intermediates do not displace the tracer thrombin. If pure intermediates were assayed in buffer, they might react with the antibody, as bovine prothrombin and intermediates react with antibodies to prothrombin and intermediates (35). Considering the marked antigenic difference between thrombin and prothrombin, one would not expect significant cross-reactivity between thrombin and any zymogens of the other serine proteases involved in coagulation, although considerable amino acid sequence hematology has been demonstrated in the amino-terminal portions of bovine factors II, IX, and the light chain of X (26). It is possible that there is cross-reactivity between $\alpha-, \beta$-, and $\gamma$-thrombin, the latter two being degradative products of the active molecule with considerably less clotting activity than $\alpha$-thrombin. If this is the case, the results of the experiments in which thrombin levels were measured in clotting blood would be no less meaningful, since the appearance of $\beta$ - and $\gamma$-thrombin is presumably preceded by the active molecule, $\alpha$-thrombin.

It was important to establish that the small amount of what appears to be thrombin generated in the first few minutes after venipuncture was actually thrombin. The inability to detect this immunoreactive material in the presence of heparin suggests that it is thrombin rather than prothrombin intermediates, since the latter do not bind to antithrombin III. Additionally, when prothrombin was incubated with thrombin, converting it to prethrombin 1 , there was little additional immunoreactivity present other 
than the thrombin added initially (data not shown). This suggests that there was little cross-reactivity between prethrombin 1 and thrombin.

The significance of the presence of thrombin early in the clotting process is not known. It is known, however, that thrombin added in low concentrations will activate platelets $(0.01-0.1 \mathrm{U} / \mathrm{ml})$ suspended in buffer (4) or factor $\mathrm{V}(0.1-0.8 \mathrm{U} / \mathrm{ml})$ also in a buffered system (2). Factor VIII is converted to the "active" form when small amounts of thrombin (0.03-0.1 $\mathrm{U} / \mathrm{ml}$ ) are added to plasma (3). It may be that even smaller amounts of endogenously generated thrombin activate these factors in whole blood. Our experiments detected between 2 and $3 \mathrm{ng}$ of thrombin $/ \mathrm{ml}$ $(8 \mathrm{mU} / \mathrm{ml})$ plasma long before clotting occurred, an amount undetectable in previous studies of prothrombin activation. Thus, it may be that small amounts of thrombin are important in initiating clotting by activating the above factors. Further experiments are necessary to determine the precise details of the kinetics of thrombin formation. Further, we do not know whether the thrombin we measured in clotting blood represents the total amount found or whether only free thrombin is measured and that bound to the platelet receptor, clotting factors, or inhibitors is not measured.

Nossel and co-workers have indirect evidence that thrombin is present in minute amounts at the beginning of blood clotting (36). Using a radioimmunoassay for fibrinopeptides (37), formed when thrombin cleaves fibrinogen, they found increasing amounts of fibrinopeptides present from the very beginning of blood collection, indicating the presence of biologically active thrombin.

The origin of thrombin so early in the clotting process is unknown. Whether very small amounts of tissue factor released at the time of venipuncture are able to activate the extrinsic clotting pathway, resulting in thrombin formation, remains to be determined. The thrombin we are measuring in plasma is not bound to antithrombin III, as demonstrated by the experiments in which native thrombin is poorly detected by radioimmunoassay in heparinized plasma, nor by the direct assay of the thrombin-antithrombin III complex. Our experiments suggest the feasibility of studying the kinetics of activation of other factors, i.e., XI, IX, X, and their interrelationship with prothrombin activation by use of radioimmunoassay for these factors.

\section{ACKNOWLEDGMENTS}

The authors wish to thank Drs. Tim Sullivan and Charles Parker for their helpful advice in the development of the radioimmunoassay and Ms. Nancy Stanford for expert technical assistance. We also wish to thank Dr. Craig
Jackson for his many helpful discussions and advice, and Mr. Joseph Miletich for preparation of the human prothrombin.

This research was supported by grants HL-14147 (Specialized Center for Research in Thrombosis) and HL 16634 from the National Institutes of Health.

\section{REFERENCES}

1. Baughman, D. J. 1970. Thrombin assay. Methods Enzymol. 19: 145-157.

2. Colman, R. W. 1969. The effect of proteolytic enzymes on bovine factor V. I. Kinetics of activation and inactivation by bovine thrombin. Biochemistry. 8: 14381445.

3. Rappaport, S. I., S. Schiffman, M. J. Patch, and S. B. Ames. 1963. The importance of activation of antihemophilic globulin and proaccelerin by traces of thrombin in the generation of intrinsic prothrombinase activity. Blood. 21: 221-236.

4. Shuman, M. A., D. M. Tollefsen, and P. W. Majerus. 1976. The binding of human and bovine thrombin to human platelets. Blood. 47: 43-54.

5. Mann, K. G., C. M. Heldebrant, and D. N. Fass. 1971. Multiple active forms of thrombin. II. Mechanisms of production from prothrombin. J. Biol. Chem. 246: 6106-6114.

6. Stenn, K. S., and E. R. Blout. 1972. Mechanism of bovine prothrombin activation by an insoluble preparation of bovine factor $\mathrm{X}_{\mathrm{a}}$ (thrombokinase). Biochemistry. 11: $4502-4515$.

7. Heldebrant, C. M., R. J. Butkowski, S. P. Bajaj, and K. G. Mann. 1973. The activation of prothrombin. II. Partial reactions, physical and chemical characterization of the intermediates of activation. J. Biol. Chem. 248: 7149-7163.

8. Owen, W. G., C. T. Esmon, and C. M. Jackson. 1974. The conversion of prothrombin to thrombin. I. Characterization of the reaction products formed during the activation of bovine prothrombin. J. Biol. Chem. 249: 594-605.

9. Esmon, C. T., W. G. Owen, and C. M. Jackson. 1974. The conversion of prothrombin to thrombin. II. Differentiation between thrombin- and factor $\mathrm{X}_{\mathrm{a}}$-catalysed proteolyses. J. Biol. Chem. 249: 606-611.

10. Silverberg, S. A., and Y. Nemersen. 1975. The control of prothrombin conversion. Kinetic control by mechanisms inherent in two activation pathways. Biochemistry. 14: 2636-2644.

11. Rosenberg, J. S., D. L. Beeler, and R. D. Rosenberg. 1975. Activation of human prothrombin by highly purified human factors $\mathrm{V}$ and $\mathrm{X}_{\mathrm{a}}$ in the presence of human antithrombin. J. Biol. Chem. 250: 1607-1617.

12. Downing, M. R., R. F. Butkowski, M. M. Clark, and K. G. Mann. 1975. Human prothrombin activation. $J$. Biol. Chem. 250: 8897-8906.

13. Fasco, M. J., and J. W. Fenton, II. 1973. Specificity of thrombin. I. Esterolytic properties of thrombin, plasma, trypsin, and chemotrypsin with $\mathrm{N}_{\mathrm{B}}$-substituted guanidino derivitives of $p$-nitrophenyl-p'-guanidino benzoale. Arch. Biochim. Biophys. 159: 802-812.

14. Glover, G., and E. Shaw. 1971. The purification of thrombin and isolation of a peptide containing the active center histidine. J. Biol. Chem. 246: 4594-4601.

15. Bachmann, F., F. Duckert, and F. Koller. 1958. The Stuart-Prower factor assay and its clinical significance. Thromb. Diath. Haemorrh. 2: 24-38. 
16. Yin, E. T., L. Eisenkramer, and J. V. Butler. 1975. Heparin interaction with activated factor $\mathrm{X}$ and its inhibitor. Adv. Exp. Med. Biol. 52: 239-242.

17. March, S. C., I. Parikh, and P. Cautrecasas. 1974. A simplified method for cyanogen bromide activation of agarose for affinity chromatography. Anal. Biochem. 60: $149-152$.

18. Kurachi, K., G. Schmer, M. A. Hermodson, D. C. Teller, and E. W. Davie. 1976. Characterization of human, bovine, and horse antithrombin III. Biochemistry. 15: 368-373.

19. Hunter, W. M. 1967. The preparation of radioiodinated proteins of high activity. In Handbook of Experimental Immunology. D. M. Weir, editor. Blackwell Scientific Publications Ltd., Oxford. 608-654.

20. Seegers, W. H., and H. P. Smith. 1942. Factors which influence the activity of purified thrombin. Am.J. Physiol. 137: 348-354.

21. Straughn, W., III, and R. H. Wagner. 1966. A simple method for preparing fibrinogen. Thromb. Diath. Haemorrh. 16: 198-206.

22. Task force on the nomenclature of blood clotting zymogens and zymogen activation products. 1976. Preliminary report. Thromb. Diath. Haemorrh. In press.

23. Fujikawa, K., M. H. Coan, D. L. Enfield, K. Titani, L. H. Ericssen, and E. W. Davie. 1974. A comparison bovine prothrombin, factor IX (Christmas factor), and factor X (Stuart factor). Proc. Natl. Acad. Sci. U. S. A. 71: $427-430$.

24. Rosenberg, R. D., and P. S. Damus. 1973. The purification and mechanism of action of human antithrombinheparin cofactor. J. Biol. Chem. 248: 6490-6505.

25. Densen, K. W. E. 1967. The use of antibodies in the study of blood coagulation. F. A. Davis Company, Philadelphia, Pa. 244 pp.

26. Schmer, G., E. P. Kirby, D. C. Teller, and E. W. Davie. 1972. The isolation and characterization of bovine fac- tor VIII (antihemophilic factor) J. Biol. Chem. 247: $2512-2521$.

27. Shapiro, S. S. 1968. Human prothrombin activation. Immunochemical study. Science (Wash. D. C.). 162 127-129.

28. Prydz, H. 1965. Studies on proconvertin (factor VII) VI. The production in rabbits of an antiserum against factor VII. Scand. J. Clin. Lab. Invest. 17: 66-72.

29. Legaz, M. E., G. Schmer, R. B. Counts, and E. W. Davie. 1973. Isolation and characterization of human factor VIII (antihemophilic factor). J. Biol. Chem. 248: 3946-3955.

30. Prydz, H., and $\AA$. Gladhaug. 1971. Factor X Immunological studies. Thromb. Diath. Haemorrh. 25: 157- 165.

31. Davis, A. D., R. F. Murphy, and D. T. Ellmore. 1974 A radioimmunoassay of bovine factor X. Biochem. Soc. Trans. 2: 738-739. (Abstr.).

32. Hoyer, L. W. 1972. Immunologic studies of antihemophilic factor (AHF factor VIII). IV. Radioimmunoassay of AHF antigen. J. Lab. Clin. Med. 80: 822-833.

33. Bohn, H. 1972. Comparative studies on the fibrinstabilizing factors from human plasma, platelets and placentas. Ann. N. Y. Acad. Sci. 202: 256-272.

34. Hart, A., K. C. Robbins, L. Summaria, and S. F. Rabiner 1971. Differentiation of plasminogen from plasmin by radioimmunoassay. Fed. Proc. 30: 367. (Abstr.).

35. Taswell, C., F. C. McDuffie, and K. G. Mann. 1975. Immunochemical relationships of the intermediates of prothrombin activation. Immunochemistry 12: 339-343.

36. Nossel, H. L., M. Tai, K. L. Kaplan, K. Spanondis, T, Soland, and V. P. Butler, Jr. The generation of fibrino peptide $A$ in clinical blood samples. Evidence for thrombin activity. J. Clin. Invest. 58: 1136-1144.

37. Bilezekian, S. B., H. L. Nossel, V. P. Butler, Jr., and R. E. Canfield. 1975. Radioimmunoassay of human fibrinopeptide B and kinetics of fibrinopeptide cleavage by different enzymes. J. Clin. Invest. 56: 438-445. 